Revista Multidisciplinar do Nordeste Mineiro, v.2 2019/02

ISSN 2178-6925

\title{
OS PRECEDENTES JUDICIAIS E SUA EFICÁCIA PARA GARANTIA DA SEGURANÇA JURÍDICA
}

\section{JUDICIAL PRECEDENTS AND THEIR EFFICIENCY FOR LEGAL SECURITY GUARANTEE}

\section{Sâmara Camisão Pechir}

Pós Graduada em Direito Penal e Direito Processual Penal pelo Instituto Damásio de Direito. Atua como advogada há 03 anos nas áreas de Direito Civil, Direito Penal, Direito Trabalhista e Previdenciário.

\section{Luana Pacheco Guimarães}

Pós Graduada em Direito Público pela Universidade Anhanguera de São Paulo nas áreas de Direito Constitucional, Administrativo, Tributário e Previdenciário, atua como advogada há 07 anos nas áreas de direito civil , administrativo e previdenciário, exerce atividade de Magistério junto a Faculdade Presidente Antônio Carlos de Teófilo Otoni/MG.

\section{Resumo}

O presente artigo tem como finalidade discorrer acerca do sistema de precedentes judiciais introduzidos pelo Novo Código de Processo Civil e sua eficácia a fim de garantir segurança jurídica. Cuida-se de pesquisa bibliográfica e documental onde se analisou a opinião de diferentes doutrinadores e a legislação pátria. Inicialmente, preocupou-se em conceituar e comparar o sistema Civil Law, este adotado pelo Brasil onde impera a legislação escrita e o sistema Common Law que tem como fonte principal do direito os costumes. A partir disso, veremos posicionamentos de juristas contra e a favor da adoção do sistema de precedentes obrigatórios pelo Brasil. Finalmente, vamos analisar o uso de precedentes pelo judiciário Brasileiro, visando demonstrar a importância de unificar decisões judiciais a fim de garantir segurança jurídica para a sociedade, criando um judiciário mais previsível, sem decisões surpresa.

Palavras-chave: Precedentes Judiciais. Civil Law. Common Law. Segurança Jurídica. Celeridade.

\section{Abstract}

The purpose of this article is to discuss the system of judicial precedents introduced by the New Code of Civil Procedure and its effectiveness to ensure legal certainty. Take care of research bibliographic and documentary analysis where the opinion of the different indoctrinators and the national legislation were analyzed. Initially, he was 
concerned with conceptualizing and comparing the Civil Law system, which was adopted by Brazil where written law and the Common Law system whose main source of law is customs. Starting In addition, we will see legal positions against and in favor of the adoption of the mandatory precedent system for Brazil. Finally, we will analyze the use of precedents by the Brazilian judiciary, aiming to demonstrate the the importance of unifying court decisions in order to ensure legal certainty for society by creating a more predictable judiciary, no surprise decisions.

Keywords: Judicial Precedents. Civil Law. Common Law. Legal Security. Speed.

\section{Introdução}

Esse estudo tem como objetivo analisar o sistema de precedentes judiciais inserido no Novo Código de Processo Civil e sua eficácia a fim de garantir a segurança jurídica.

O Brasil adota o sistema jurídico Civil Law, da mesma forma que os países de origem romano-germânica. Esse sistema tem a lei escrita como fonte primária do direito, sendo que o juiz atua como intérprete e aplicador dessas leis.

Por outro lado, há o sistema jurídico Common Law de onde deriva a teoria dos precedentes, objeto de estudo desse trabalho. No Common Law, também conhecido como sistema anglo-saxão, os julgadores fundamentam suas decisões principalmente em costumes. Isso não que dizer que o sistema Civil Law não utilize de precedentes, entretanto, estes possuem a finalidade de orientar o julgador, não estando ele vinculado ao precedente (NEVES, 2017).

A novidade é que no Novo Código de Processo Civil, os artigos 926 e 927 estabeleceram um sistema de precedentes que tem como base o Common Law. No novo ordenamento a lei deixou de ser a única que vincula o julgador, estando previsto também um rol de decisões que servirão de precedentes e vinculará o juiz.

As opiniões dos juristas divergem acerca da segurança jurídica oferecida por esse sistema jurídico, havendo argumentos contrários e a favor. Para Donizetti (2017, p. 1472) o sistema de precedentes:

As técnicas que valorizam os precedentes judiciais e, consequentemente, a celeridade processual, a isonomia e a segurança jurídica devem servir para aprimorar o sistema processual civil e jamais para engessar a atuação interpretativa dos juízes e tribunais pátrios ou para limitar o direito de acesso à justiça. 
Desta forma, pretende-se demonstrar ao longo do trabalho os benefícios da adoção do sistema de precedentes inserido no Código de Processo Civil sob o aspecto da segurança jurídica que este pode oferecer à sociedade. Para alcançar os objetivos propostos, utilizou-se como recurso metodológico, a pesquisa bibliográfica, realizada a partir da análise pormenorizada de doutrinas e da legislação pátria.

\section{Desenvolvimento}

Conforme leciona Alexandre Freitas Câmara (2017, p. 367) "precedente é um pronunciamento judicial, proferido em um processo anterior, que é empregado como base da formação de outra decisão judicial, prolatada em processo posterior", isto é, toda vez que um órgão jurisdicional, fundamenta sua decisão em outro julgamento já transitado em julgado, este último será o precedente.

$\mathrm{Na}$ atualidade o sistema processual civil brasileiro vem sofrendo grandes modificações, entre elas, o despontamento no nosso sistema jurisdicional Civil Law de um outro modelo de precedentes relacionado ao Commom Law.

Tais modelos jurisdicionais possuem diferenças expressivas. $O$ sistema Common Law normalmente adotado por países Anglo-Saxão, consiste na aplicação dos costumes ao direito, isto é, em casos jurídicos parecidos, em que o direito discutido já tenha sido objeto de análise do judiciário, a decisão do juiz deve ser semelhante a anterior, assim os julgamentos não ficam limitadas as partes, podendo ganhar maior abrangência caso ocorram acontecimentos parecidos.

Desta forma, quando as partes divergem quanto ao direito aplicado ao caso concreto, institivamente o juiz irá buscas por decisões anteriores de tribunais competentes, que se assemelham ao caso concreto. Uma vez constatado que houve conflito parecido previamente, o julgador é obrigado a seguir o entendimento utilizado naquela decisão, o que é conhecido como princípio do stare decisis. Importante esclarecer que a decisão só se torna um precedente no momento em passa a servir como fundamento de decisão a outros julgamentos (NEVES, 2017).

No Brasil é adotado o sistema jurídico denominado Civil Law ou Sistema Romano-Germânico onde a lei é a fonte primária do ordenamento jurídico. No nosso sistema, o juiz atua como intérprete e aplicador da lei, para Medina (2015, p. 819) o Civil Law confere ao juiz mais liberdade, uma vez que este não está subordinado a nenhum precedente de órgão superior. Nesse sentido, pondera o autor: 
Embora muitos possam afirmar que o estabelecimento de direito e deveres por meio de leis escritas traz maior segurança aos cidadãos (já que o exercício da jurisdição estaria legal e previamente balizado), é inegável que, hoje, o juiz brasileiro tem muito mais poder de criação que o juiz do commom law, tendo em vista que, ao contrário deste último, aquele, em princípio, não deveria (pelo menos, à luz da letra de nossa legislação) nenhum respeito aos precedentes judiciais dos tribunais ou órgãos que lhe sejam superiores.

A adoção do sistema Civil Law pelo Brasil veio prevista na Constituição Federal de 1988 ao estabelecer que "ninguém será obrigado a fazer ou deixar de fazer alguma coisa senão em virtude de lei". Da referida norma, advém o princípio da legalidade, que norteia as decisões judiciais fazendo com que estas respeitem a lei (DONIZETI, 2017).

Ressalta-se que no sistema Civil Law, apesar do predomínio das leis, há também os precedentes judiciais, assim como no sistema anglo-saxão. A distinção encontra-se no fato de que no Civil Law, os precedentes têm como finalidade orientar a interpretação da lei, não necessariamente obrigando o julgador a seguir aquela orientação.

Ocorre que as coisas vêm mudando no sistema legal Brasileiro, cada vez mais juízes de instâncias inferiores estão sendo compelidos a adotar orientações de tribunais superiores, a título de exemplo podemos citar as súmulas vinculantes, o julgamento em controle abstrato de constitucionalidade e o julgamento de recursos repetitivos.

Com o advento do Novo Código de Processo Civil (Lei ํㅜ 13.105, de 16 de março de 2015) este enlace é ainda mais evidente, o legislador positivou algumas diretrizes a fim de adequar o entendimento dos tribunais superiores em todos os níveis jurisdicionais, evitando assim, o afastamento da jurisprudência das instâncias inferiores (DONIZETI, 2017).

A lei perdeu um pouco a sua supremacia e já não é a única a vincular o julgador. Com o novo $\mathrm{CPC}$, os precedentes também passaram a vincular as decisões judiciais, uma vez que o diploma legal prevê expressamente que não reputa fundamentada a decisão que deixar de observar precedente, súmula ou jurisprudência invocada pela parte, sem mostrar que o direito não se aplica ao caso concreto. Eis o artigo 489, § 1ㅇ, $\mathrm{VI}, \mathrm{CPC}$ : 
Art. 489. (...).

$\S 10$ Não se considera fundamentada qualquer decisão judicial, seja ela interlocutória, sentença ou acórdão, que:

(...)

VI deixar de seguir enunciado de súmula, jurisprudência ou precedente invocado pela parte, sem demonstrar a existência de distinção no caso em julgamento ou a superação do entendimento.

Deixando de lado toda a acirrada discussão doutrinária acerca da validade dos artigos 926 e 927 do CPC, pois não constitui objeto deste estudo, os referidos artigos consolidaram o regime de precedentes obrigatórios no sistema jurídico Brasileiro, norma fundada no princípio da segurança jurídica (MACEDO, 2016). artigo 926 do CPC trouxe instruções aos tribunais acerca da necessidade de uniformização de jurisprudência, a fim de conferir mais estabilidade jurídica à sociedade, in verbis:

Art. 926. Os tribunais devem uniformizar sua jurisprudência e mantê-la estável, íntegra e coerente.

$\S 1^{\circ} \mathrm{Na}$ forma estabelecida e segundo os pressupostos fixados no regimento interno, os tribunais editarão enunciados de súmula correspondentes a sua jurisprudência dominante.

$\S 2$ o Ao editar enunciados de súmula, os tribunais devem ater-se às circunstâncias fáticas dos precedentes que motivaram sua criação.

Da mesma forma o artigo 927 do CPC trouxe o rol de precedentes obrigatórios:

Art. 927. Os juízes e os tribunais observarão: I - as decisões do Supremo Tribunal Federal em controle concentrado de constitucionalidade;

II - os enunciados de súmula vinculante;

III - os acórdãos em incidente de assunção de competência ou de resolução de demandas repetitivas e em julgamento de recursos extraordinário e especial repetitivos;

IV - os enunciados das súmulas do Supremo Tribunal Federal em matéria constitucional e do Superior Tribunal de Justiça em matéria infraconstitucional;

V - a orientação do plenário ou do órgão especial aos quais estiverem vinculados.

$\S 1^{\circ}$ Os juízes e os tribunais observarão o disposto no art. 10 e no art. 489, $\S 1^{\circ}$, quando decidirem com fundamento neste artigo.

$\S 2^{\circ} \mathrm{A}$ alteração de tese jurídica adotada em enunciado de súmula ou em julgamento de casos repetitivos poderá ser precedida de audiências públicas e da participação de pessoas, órgãos ou entidades que possam contribuir para a rediscussão da tese.

$\S 3^{0} \mathrm{Na}$ hipótese de alteração de jurisprudência dominante do Supremo Tribunal Federal e dos tribunais superiores ou daquela oriunda de julgamento de casos repetitivos, pode haver modulação dos efeitos da alteração no interesse social e no da segurança jurídica.

§ 4ํA modificação de enunciado de súmula, de jurisprudência pacificada ou de tese adotada em julgamento de casos repetitivos observará a necessidade de fundamentação adequada e específica, considerando os 
princípios da segurança jurídica, da proteção da confiança e da isonomia. $\S 5^{\circ}$ Os tribunais darão publicidade a seus precedentes, organizando-os por questão jurídica decidida e divulgando-os, preferencialmente, na rede mundial de computadores.

Sendo assim, estando presentes os requisitos dos artigos 489, 926 e 927 do CPC e sendo o caso concreto semelhante a um precedente, o julgador ficará vinculado ao precedente conferindo à sociedade maior segurança jurídica às decisões.

Os defensores do sistema Civil Law pregam a ideia de que a segurança jurídica está ligada a um texto escrito promulgado, estando o juiz subordinado a este texto. Entretanto, conforme assevera Daniel Amorim Neves (2017) a lei pode sofrer interpretações diversas, sendo que experiências de vida e percepções morais do julgador podem influenciar na decisão.

O sistema de precedentes visa oferecer soluções idênticas a acontecimentos idênticos ou soluções semelhantes para casos que demandam o mesmo fundamento jurídico, evitando o uso excessivo de recursos e o aumento na quantidade de demandas (DONIZETI, 2017).

Se uma mesma norma legal recebe interpretações jurisdicionais distintas, não há segurança jurídica, por outro lado, quando uma decisão é tomada com base em um entendimento anterior, o juiz não terá a necessidade de correr o risco de produzir uma decisão injusta ou reproduzir grandes argumentos, bastando adequar o precedente ao caso concreto. Nesta senda, José Miguel Garcia Medina (2015, p. 819) esclarece que o sistema de precedentes:

\footnotetext{
A adoção de um regime de respeito aos precedentes judiciais justifica-se por diversas razões. Ele traz segurança jurídica, previsibilidade, estabilidade, desestímulo à litigância excessiva, confiança, igualdade perante a jurisdição, coerência, respeito à hierarquia, imparcialidade, favorecimento de acordos, economia processual (de processos e de despesas) e maior eficiência.
}

Outra vantagem do sistema de precedentes é que eles impedem o uso excessivo de recursos. De fato, sendo a decisão judicial fundamentada em precedente se torna inútil a impetração de recurso para debater o que já está consolidado, e consequentemente, isto tornará a justiça mais célere. É o que ocorre com os precedentes consolidados em súmulas do Supremo Tribunal Federal e Superior Tribunal de Justiça (CARON, s.d.). 
Há ainda na doutrina brasileira, aqueles que não concordam com o uso de precedentes judiciais sob o discurso que nesse tipo de sistema o direito fica engessado, tendo em vista que ao estabelecer um padrão, o direito ficaria impedido de evoluir, por esse motivo, para os defensores dessa corrente, os precedentes deveriam servir apenas como um referencial, não estando os magistrados obrigatoriamente vinculados a eles. Outro argumento, é que o sistema de precedentes tiraria a independência funcional dos magistrados, já que estes estariam obrigatoriamente vinculados a eles (CARON, s.d.).

Para Elpídio Donizetti (2017) a previsibilidade das decisões do judiciário não causará a "fossilização" do sistema jurídico, haja vista que os magistrados continuarão decidindo conforme as provas no processo. Nessa sequência, o autor expôs que:

\footnotetext{
Podemos dizer, então, que no âmbito do nosso sistema jurídico, afora outros

objetivos, os precedentes judiciais visam "alcançar a exegese que dê certeza aos jurisdicionados em temas polêmicos, uma vez que ninguém ficará seguro de seu direito ante jurisprudência incerta". Oportuno observar que a previsibilidade do resultado de certas demandas não acarretará a "fossilização" do Poder Judiciário, pois os processos que digam respeito a questões de fato continuarão a ser decididos conforme as provas apresentadas no caso concreto. Além disso, os tribunais poderão modificar precedentes já sedimentados, desde que o façam em decisão fundamentada (DONIZETE, 2017, p. 1461).
}

No sistema jurídico Brasileiro atual impera a insegurança jurídica e a desconfiança da população no judiciário. Isso porque quem impetra uma demanda achando que possui o mesmo direito que seu vizinho que conseguiu sentença favorável, em situação semelhante, corre o risco de frustra-se e obter uma sentença totalmente contrária, isso porque cada juiz pode ter um entendimento diferente.

Não quer dizer também que o sistema de precedentes adota a eternização de decisões, o magistrado continuará com sua autonomia e livre convencimento, afastando a norma legal quando ela não for adequada ao caso concreto, tudo irá depender da sua fundamentação (CÂMARA, 2017).

Pelos motivos apresentados, o uso de precedentes no sistema jurídico Brasileiro trará para a população segurança jurídica, pois haverá julgamentos repetitivos para demandas repetitivas, equidade nas decisões e consequentemente, segurança jurídica. 
O atual judiciário está abarrotado e insustentável para juízes, servidores e principalmente para população, que é quem mais sofre com essa situação. Por esse motivo, o novo Código de Processo Civil acertou em introduzir o sistema de precedentes processuais com a finalidade de garantir a tão sonhada segurança jurídica.

\section{Considerações finais}

De todo o exposto considerou-se que o novo regime de precedentes jurisdicionais inaugurou uma nova fase no Processo Civil Brasileiro, em que as decisões proferidas não se limitam àquela lide. As críticas levantadas sobre esse sistema são infundadas, uma vez que o próprio sistema apresenta soluções para eventuais falhas processuais, sendo que os benefícios indubitavelmente sobrepõem os pontos negativos.

O sistema de Civil Law causa uma grande insegurança jurídica na sociedade, uma vez que viola um dos princípios constitucionais mais importantes: a igualdade. Ora, se todos são iguais perante a lei por qual motivo duas pessoas teriam resultados distintos em suas demandas judiciais, em casos iguais. É o que ocorre no nosso judiciário.

Finalmente, a introdução do sistema de precedentes do Common Law tornará o judiciário mais previsível, evitando assim decisões surpresa. Trata-se de um grande passo a fim de alcançarmos um sistema judiciário com mais equidade e segurança jurídica, além de coerência, celeridade e isonomia.

\section{Referências}

BRASIL. Código de Processo Civil. LEI FEDERAL № 13.105, de 16.03.2015. Disponível em: <http://www.planalto.gov.br/ccivil_03/_ato20152018/2015/lei//13105.htm>. Acesso em09.04.2018.

BRASIL. Constituição da República Federativa do Brasil. Brasília, DF: Senado Federal, 1988. Disponível em: <http://www.planalto.gov.br/ccivil_03/constituicao/constituicaocompilado.htm>. Acesso em: 06.04.2018

CÂMARA, Alexande Freitas. O novo processo civil brasileiro. 3. Ed. São Paulo: Atlas, 2017. 
CARON, Débora. Teoria dos precedentes judiciais e sua eficácia para garantia da segurança jurídica. Revista da Faculdade de Direito da Universidade Federal de Uberlândia. v. 42 n. 1 (2014)

DONIZETTI, Elpídio. Curso didático de direito processual civil. 20 ed. São Paulo: Atlas, 2017.

MACÊDO, Lucas. Buril. De. Precedentes judiciais e o Direito Processual Civil. Salvador: JusPodivm, 2016.

MEDINA, José Miguel Garcia. Novo Código de Processo Civil Comentado. 1 ed. São Paulo: Editora Revista dos Tribunais, 2015.

NEVES, Daniel Amorim Assumpção. Manual de direito processual civil. 9ed. Salvador: Ed. JusPodvim, 2017. 